\footnotetext{
Resumo

A maioria das crianças e dos adolescentes que vivem sob a proteção da juventude viveram traumas complexos ligados à negligência, aos maus tratos e às diversas formas de abusos. Sugerimos que esses jovens, bem como seus pais, apresentam dificuldades quanto à capacidade de mentalização e demonstram um funcionamento psíquico característico dos modos de pensar pré-mentalizantes. Este artigo apresenta a operacionalização dos diferentes modos de pensar (teleológico, de equivalência psiquica e fictício). São apresentados os princípios subjacentes a um programa de intervenção baseado na mentalização que poderão ser utilizados pelos educadores que trabalham com crianças $e$ adolescentes em situação de vulnerabilidade.

Descritores: mentalização; trauma; modos de pensar pré-mentalizantes; intervenção baseada na mentalização.
}

\section{SOFRIMENTO NOS \\ LAÇOS PAIS-FILHOS: PRÁTICAS EDUCATIVAS FUNDADAS NA MENTALIZAÇÃO NA PROTEÇÃO DA INFÂNCIA}

Miguel M. Terradas Julie Achim

Tradução: Inesita Machado

DOl: http//dx.doi.ors/10.11606/issn. 1981-1624.v21i1p170-188.

A s crianças e adolescentes sob a responsabilidade da proteção da juventude viveram, em sua maioria, traumas complexos. Estes foram expostos a múltiplos eventos traumáticos ocorridos precocemente em suas relações interpessoais significativas, de modo repetido e prolongado. As figuras principais de apego, em geral os pais, são constantemente as que infligem maus tratos às crianças (Herman, 1992; Courtois, 2004).

Psicólogo. Professor do Departamento de Psicologia da Universidade de Sherbrooke, Quebec, Canadá.

- - Psicóloga. Professora do Departamento de Psicologia da Universidade de Sherbrooke, Quebec, Canadá. 
Os traumas vividos durante a infância teriam impactos maiores no desenvolvimento da criança e do adolescente. Assim, muitas das crianças que vivem com famílias de acolhimento, em abrigos grupais ou em centros de readaptação, apresentam, no momento de seu atendimento pela proteção da juventude, sintomas comparáveis aos de uma população clínica (Fernandez, 2008). Segundo Allen (2001), a severidade e a diversidade dos impactos observados em jovens que viveram tais traumas seriam explicadas pelo fato de que eles se inscrevem na relação de apego entre a criança e seus pais que não estariam em condições de assumir suas funções de segurança e de proteção de seu filho. As carências e traumas vividos nessa relação levariam ao desamparo da criança e ao comprometimento do desenvolvimento de sua capacidade mental e interpessoal, sendo estas essenciais para a regulação de tal desamparo (Allen, 2001).

Quando o genitor é a própria fonte do medo ou das emoções negativas vividas pela criança, ela corre o risco de gerar um padrão relacional problemático na relação de apego. Assim, o desamparo causado pelo genitor ativa a necessidade de proximidade da criança, que, por sua vez, tentará se aproximar do genitor. Isso terá como efeito o aumento dos afetos negativos vividos pela criança. A criança terá então grande necessidade de uma relação que a amedronta e o genitor estará sendo, ao mesmo tempo, fonte de desamparo e de reconforto (Allen, 2013).

As crianças e adolescentes que viveram grandes traumas relacionais têm mais chance de ter seu desenvolvimento comprometido, de apresentar sintomas clínicos, de ter dificuldade diante de eventuais situações dolorosas, bem como de viver grandes dificuldades relacionais. Apesar da diversidade de patologias apresentadas, essas crianças e adolescentes têm em comum dificuldades significativas no nível de suas capacidades de auto-regulação - tanto no plano da regulação da atenção, quanto dos afetos e do comportamento. Como consequência, apresentam um funcionamento psíquico e relacional sob o signo do agir, mais do que do da palavra, do pensamento e da simbolização (Terradas \& Achim, 2014). 
Diante de tais dificuldades, o recurso aos instrumentos terapêuticos habituais associados à psicoterapia psicanalítica dita clássica parece pouco adaptado, ou pelo menos parece ter alcance limitado, já que se baseia no equipamento psíquico que essas crianças e adolescentes - e muitas vezes seus pais - não desenvolveram suficientemente. Assim, é preciso inventar novas modalidades que deem conta dessa realidade clínica, bem como do nível de desenvolvimento psíquico desses jovens (Terradas \& Achim, 2014). Para melhor compreender as dificuldades apresentadas por essas crianças, assim como as de seus pais, a noção de mentalização tem muita utilidade.

\section{Mentalização, um elemento essencial para compreender-se e compreender o outro}

A mentalização se refere à capacidade de um indivíduo de perceber e interpretar seu comportamento e o de outrem em termos de estados mentais (Allen, Fonagy, \& Bateman, 2008). São considerados estados mentais os pensamentos, os sentimentos, as expectativas e as intenções. Quando o indivíduo é capaz de identificar e atribuir estados mentais, ele pode atribuir sentido a seus próprios atos, bem como aos das pessoas que o cercam. A mentalização permite que ele torne seu comportamento, o de outrem e suas relações interpessoais compreensíveis, previsíveis e portadoras de sentido (Allen et al., 2008). A mentalização também ajuda o indivíduo a melhor compreender e regular suas emoções e assim, regular seu comportamento (Fonagy et al., 1995).

A capacidade de mentalização se desenvolve no contexto da relação de apego entre a criança e seu pai ou sua mãe (Allen et al., 2008). O apego de tipo seguro, caracterizado pela sensibilidade e pela empatia do genitor em relação a seu filho, seria uma condição ótima, mas não suficiente, para o desenvolvimento da capacidade de mentalização. É necessário que o genitor, por meio 
das interações com a criança, emita comentários apropriados sobre os estados mentais dessa última. O genitor dirigiria assim a atenção da criança para a existência e, eventualmente, para o significado dos estados mentais (Allen et al., 2008); para isso, o genitor deve estar de acordo com a criança para lhe transmitir uma resposta afetiva e comportamental que é, ao mesmo tempo, semelhante (já que ela traduz o desamparo da criança) e distinta (já que ela se expressa de modo mais elaborado) daquela manifestada pela criança (Fonagy, Gergely, Jurist \& Target, 2002).

A mentalização, como definida por Fonagy e Target em uma série de artigos referência publicados entre 1996 e 2007 (Playing with reality I, II, III e IV), baseia-se em diversas noções elaboradas por outros psicanalistas britânicos, principalmente Winnicott (por exemplo, "função espelho", "mãe suficientemente boa", "holding").

Winnicott (1945) sugere que o desenvolvimento afetivo da criança começa imediatamente após o nascimento. As experiências sensoriais (sons, percepções, movimentos, gostos, cheiros), quase sempre ligados à mãe, são vividas como pedaços por uma personalidade nascente não integrada. Assim, a criança precisa de uma retroação da mãe sobre essas experiências parciais para sentir que elas existem. É graças à função espelho (Winnicott, 1971) exercida pela mãe que a criança irá desenvolver os primeiros traços mnésicos de sua experiência afetiva, o que lhe permitirá construir progressivamente um conjunto de representações mentais. A qualidade suficientemente boa da relação entre a criança e sua figura de apego permitirá ao genitor garantir uma função continente (bolding) com a criança que, por sua vez, ver-se-á em medida de representar essas experiências internas e de aprender a regular suas emoções. Com efeito, segundo Winnicott (1963), o bebê precisa ser cuidado, acalentado e precisa ouvir uma voz calma e capaz de nomear as diversas situações que ele experimenta. Essas experiências de continência, ao mesmo tempo psicológicas e físicas, permitem-lhe desenvolver um funcionamento simbólico e uma organização do self e do self em relação.

De acordo com as observações de Winnicott (1945), é em torno dos cinco ou seis meses que o recém-nascido realiza ações com um pouco mais de sentido, o que nos leva a crer em uma possível compreensão do fato de que os objetos tenham um interior e um exterior. Por exemplo, podemos pensar que quando a criança lança repetidamente um objeto com o qual ela brinca em seu berço para fora do alcance de seu campo de visão e que sua mãe o devolve, poderia haver aí duas intenções (nascentes), ou seja, a confirmação de que esse objeto não lhe pertence no sentido da diferenciação eu-não-eu e que o retorno do objeto para seu campo de visão depende da presença de um outro (a 
mãe); essa compreensão testemunha seu reconhecimento da existência de outrem. Pouco a pouco, o bebê começa a compreender que esse outro, geralmente a mãe, também tem um interior, e ele se torna curioso em relação a isso; ele se interessa pelo que ela exprime. Em seguida, se tudo se passa suficientemente bem na relação mãe-bebê, o bebê poderá integrar suas diversas experiências relacionais, o que lhe permitirá sentir que ele é uma pessoa inteira e desenvolver um sentimento de si e de outrem. Finalmente, a criança entra na fase do desenvolvimento necessária à separação da mãe e à realização dos aspectos pertencentes ao "eu" versus àqueles que compõem o "não-eu", o que o auxiliará a estabelecer as relações de objeto (Winnicott, 1963).

A partir das ideias de Winnicott, Fonagy e Target $(1996,2000,2007)$ propõem um modelo de desenvolvimento da capacidade de mentalização. Esse modelo oferece uma compreensão do funcionamento psíquico da criança desde o nascimento até a idade de 5 anos, indo além de uma concepção dos determinantes próprios da relação mãe-filho para se interessar mais especificamente aos modos de pensar que predominam na criança antes da integração da capacidade de mentalização. Assim, os autores sugerem a existência de três modos pré-mentalizantes que caracterizam o funcionamento mental da criança pequena, os modos teleológico, de equivalência psíquica e fictício. Esses modos são integrados em torno dos 4 ou 5 anos para dar origem à capacidade de mentalização. A criança se torna então capaz de considerar que seus sentimentos, pensamentos e intenções são apenas representações da realidade externa, mais do que seu reflexo fiel.

O modo teleológico se desenvolve entre o nascimento e a metade do segundo ano de vida. Ele se caracteriza por uma representação mecanicista e racional dos motivos subjacentes a uma ação, concebidos em termos de efeitos visíveis e concretos. Para a criança, um gesto é feito simplesmente para se obter o resultado que ele provoca ou que a criança espera que ele produza. O modo teleológico é baseado nas observações da criança pequena quanto ao comportamento de outrem. Essas 
informações lhe permitem fazer suas primeiras inferências relativas aos outros e ao ambiente, sem com isso considerar seus estados mentais. A compreensão de seu comportamento e do de outros se limita, portanto, às consequências físicas (reais, tangíveis e observáveis) que ele provoca, mais do que às motivações subjacentes a esses comportamentos (Allen et al., 2008; Gergely, 2003).

O modo de equivalência psíquica caracteriza o funcionamento mental da criança entre um e três anos. Quando essa modalidade predomina, a realidade interna da criança predomina sobre a realidade externa. Sem ser percebidos como representações mentais da realidade, os estados mentais são confundidos com ela. A criança não compreende ainda que o que se passa em sua mente vem de sua vida interior e não necessariamente da realidade externa (Alle et al., 2008; Gergely, 2003). Como ela ainda não adquiriu plenamente a distinção eu-outro, a criança tende a crer que o que ela sabe também é sabido pelo outro, e o que o outro sabe lhe é acessível (Fonagy \& Target, 2007).

Como os pensamentos e os sentimentos vividos como reais podem se tornar aterrorizantes, a criança desenvolve, em torno dos três anos, um modo alternativo de compor com as realidades interna e externa, ou seja, o modo fictício. O desenvolvimento de sua capacidade em fazer semblante permite à criança compreender que há uma diferença entre seu mundo interno e o mundo externo. Enquanto essa diferença não está completamente adquirida, esses dois mundos devem ser mantidos separados, pois o confronto com 
a realidade (externa) inibe a imaginação da criança. Com efeito, o modo fictício existe enquanto realidade privada, completamente separada da realidade exterior (Fonagy \& Target, 2007), é sentida pela criança como algo sem consequências para a realidade externa (Allen et al., 2008; Gergely, 2003).

Enfim, a integração desses modos de pensar permite o desenvolvimento da capacidade de mentalização. A criança compreende então que os outros, como ela mesma, são habitados por pensamentos e sentimentos - e, portanto, por uma realidade interna - que estão ligados à realidade externa. O desenvolvimento do jogo do semblante, bem como a participação ativa do pai ou da mãe nesse jogo, permite que a criança gradualmente compreenda que esses estados mentais representam sua realidade interna e seu modo de representar o mundo que a cerca, mas não como cópias fiéis da realidade externa (Fonagy \& Target, 2000). É principalmente pelo jogo que a criança consegue, com ajuda de um dos pais, apoiar e integrar as modalidades pré-mentalizantes (Fonagy \& Target, 1996). Quando um dos pais facilita e tolera a expressão dos estados mentais pelo jogo, ele ajuda a criança a compreender que suas ações não têm consequências imediatas sobre a realidade. Assim, o jogo lhe permitirá modular, e até mesmo modificar seus estados mentais e os comportamentos a eles ligados para uma melhor adaptação.

Entretanto, o que se passa em um contexto de vulnerabilidade quando houve trauma dentro da relação de apego genitor(a)-criança? O desenvolvimento da capacidade de mentalização seria inibido em crianças que evoluem em um meio de cuidados disfuncional (Gergely, 2003). Allen (2001) sugere que um trauma ocorrido no contexto da relação de apego provoca na criança uma aversão em explorar seus estados mentais, do mesmo modo que os de outrem e, consequentemente, um retraimento do mundo mental, percebido pela criança como de muito sofrimento. Efetivamente, seria muito desorganizador para uma criança conceber que seus genitores possam lhe infringir dor intencionalmente (Fonagy \& Target, 2000). 
A capacidade de mentalização da criança não poderá, portanto, ser plenamente integrada e apoiada em um contexto de trauma de apego (Domon-Archambault \& Terradas, no prelo). A criança permanecerá em estágios pré-mentalizantes por distorções cognitivas e incompreensões a seu respeito, sobre outrem e relativas à relação que a criança mantém com outrem (Allen, et al., 2008). Ela também permanecerá vulnerável ao estresse e correndo risco de perder sua capacidade já fragilizada de pensar e de se regular (Allen, 2013).

\section{As dificuldades de mentalização de pais e de crianças em situação de vulnerabilidade}

Segundo Winnicott (1968), a mãe fracassará inevitavelmente em sua função de resposta às necessidades de seu filho, mas sua capacidade de reparar seus erros torna-a suficientemente boa. Com efeito, o autor observa que as experiências de fracasso transformadas em sucesso ajudariam a criança a se sentir em segurança. De modo similar, as experiências de privação de cuidados maternos, quando vividas de modo ocasional, permitiriam à criança experimentar a reparação (Winnicott, 1968). Nos dois casos, quando ela toma consciência de suas falhas, a mãe realiza esforços suplementares para compreender o que habita seu filho, manifestando-lhe explicitamente que ela se interessa por ele. Winnicott (1965), insiste sobre o fato de que geralmente, quando elas fracassam em responder de modo adequado às necessidades da criança, as mães não o fazem deliberadamente. Com efeito, são traços mnésicos de suas próprias experiências de criança e de cuidados maternos recebidos que influenciariam sua capacidade de cuidar de seus próprios filhos (Winnicott, 1965).

Assim, é possível que as mães que não receberam cuidados suficientemente bons ou que não tiveram a experiência da satisfação de suas próprias necessidades por um outro (sua própria mãe) possam ter mais risco de não serem capazes de responder às necessidades de seus filhos (Mikic \& Terradas, 2014). Sobre esse ponto, Winnicott (1963) considera que cada indivíduo possui um verdadeiro self que se desenvolve no contexto de um ambiente assegurador e de uma experiência de maternagem suficientemente boa. Todavia, quando uma mãe ignora as necessidades de seu filho ou as interpreta como similares às suas, ela provoca interferências (Ogden, 1983). Para se proteger de 
experiências difíceis de negligência, de abandono ou de intrusão, a criança desenvolve um segundo aspecto da personalidade, ou seja, o falso self. Essa instância teria como objetivo proteger o verdadeiro self da experiência de destruição (Winnicott, 1963). Pode-se imaginar igualmente que se a criança não recebe elementos asseguradores associados à continência, à presença de uma voz calma e à designação de objetos tanto internos (por exemplo, necessidades, sensações físicas, sentimentos), quanto externos (por exemplo, sentimentos da mãe), os diversos pedaços que constituem sua experiência seriam vividos de modo caótico. A criança teria portanto dificuldade em integrá-los em um todo coerente que lhe permitisse fazer sentido a partir de sua experiência (Mikic \& Terradas, 2014).

A noção de mentalização nos permitiria explorar ainda mais as interferências que podem ocorrer dentro da relação pais-filhos. Todavia, poucas pesquisas dizem respeito à capacidade de mentalização de pais de crianças tendo vivido traumas complexos com necessidade de intervenção da proteção da juventude. Alguns estudos realizados com mães de crianças sexualmente abusadas demonstram que sua capacidade de mentalização é significativamente mais baixa do que a de mães vindas da população geral. Esses estudos relatam que a capacidade de mentalização de mães vítimas de abusos sexuais em sua infância é mais baixa do que a de mães de crianças sexualmente abusadas que não foram elas mesmas vítimas de abuso sexual (Ensink, Normandin, Target, Fonagy, Sabourin \& Berthelot, 2015) e que uma baixa capacidade de mentalização nessas mães contribuiria para o aparecimento de sintomas depressivos na criança, bem como comportamentos sexualizados problemáticos (Ensink, Bégin, Normandin \& Fonagy, 2016). Finalmente, a capacidade de mentalização, especificamente relativa ao trauma, de mães vítimas de abuso e de negligência durante a infância, revela-se um fator importante para a resiliência dessas mães e para a qualidade das relações que elas mantêm com seus filhos pequenos e com seus parceiros (Ensink et al., 2014).

178 Estilos clin., São Paulo, v. 21, n. 1, jan./abr. 2016, 170-188. 
Outros trabalhos sobre noções conexas à capacidade de mentalização levam a crer que as crianças que crescem em contextos marcados por traumas complexos poderiam apresentar dificuldades no plano da capacidade de mentalização. Por exemplo, alguns estudos observam que as crianças que foram retiradas de seu meio familiar após uma intervenção da proteção da juventude encontram dificuldades significativas nas habilidades ligadas à teoria do espírito. Assim, Dodge, Pettit, Bates e Valente (1995) demonstraram que as crianças submetidas a uma disciplina punitiva têm mais tendência a atribuir intenções hostis aos outros quando confrontadas em situações ambíguas. Enfim, um estudo realizado por Ostler, Bahar e Jesse (2010) indica que as crianças alojadas em famílias de acolhimento, com boa capacidade de mentalização, apresentam menos sintomas internos e externos do que aquelas que têm dificuldades no plano dessa capacidade.

Ainda que, até hoje, poucos estudos tenham se interessado pela capacidade de mentalização das crianças sob a proteção da juventude, bem como a de seus pais, os trabalhos empíricos, teóricos e clínicos dedicados à noção de mentalização, bem como sua ligação ao apego e ao trauma complexo, permitem pensar que o funcionamento psíquico dessas crianças e de seus pais poderia se caracterizar pela predominância de modalidades pré-mentalizantes. No entanto, tais trabalhos se revelam importantes, de um lado, por melhor captar as particularidades do funcionamento psíquico desses indivíduos e, de outro, por desenvolver técnicas de intervenção que os leve em conta. Nesse sentido, Domon-Archambault e Terradas (2012) propuseram uma operacionalização desses diferentes modos de pensar pré-mentalizantes e identificaram comportamentos, atitudes e padrões relacionais próprios a cada um desses modos. Em seguida, elaboraram intervenções baseadas na noção de mentalização, considerando esses diversos modos de pensar destinados à intervenção em contexto de proteção da juventude. Apresentamos aqui os principais elementos.

\section{Predominância do modo teleológico}

Um funcionamento psíquico do(a) genitor(a) sob a primazia do modo teleológico se manifesta essencialmente por uma ausência de consideração dos estados mentais, tanto os próprios, quanto os dos 
filhos. Nesse contexto, o reflexo que ele proporciona à criança sobre seu estado interno estaria centrado na experiência física, concreta e real do jovem. A preponderância desse funcionamento também pode ser associada a um contexto de negligência extrema onde se pode supor que o(a) genitor(a) transmite pouco ou nenhum reflexo à criança sobre sua experiência interna.

Abandonada, a criança só pode elaborar uma representação mental de seus estados internos, que permanecerá muito próxima de suas sensações físicas. A criança que cresce em um contexto traumático não levaria em conta seus estados mentais, pois essa consideração poderia provocar nela um grande desamparo. Ela tenderia a se retirar do mundo mental já que a concepção do(a) genitor(a) como habitado(a) por estados mentais prejudiciais se revelaria (potencialmente) traumática (Allen, 2001; Fonagy \& Target, 2000). Um funcionamento predominante do modo teleológico na criança poderia se caracterizar por uma regulação afetiva baseada no corpo e marcada pela ação, a agressividade ou a superexcitação (Domon-Archambault \& Terradas, no prelo). Sua compreensão de si mesma, dos outros e do mundo que a cerca estaria centrada no observável, no tangível. Os estados mentais teriam pouca ou nenhuma importância se comparados aos comportamentos e ao meio físico (Allen et al., 2008; Verheugt-Pleiter, Zevalkink \& Schmeets, 2008).

\section{A primazia do modo de equivalência psíquica}

O pai ou a mãe, funcionando de modo predominante de equivalência psíquica, teria dificuldade em distinguir seus próprios estados mentais dos da criança. Assim, o desamparo da criança mergulharia o(a) genitor(a) em um estado de desamparo semelhante (Leroux \& Terradas, 2013). A situação inversa seria igualmente possível: quando o(a) genitor(a) se sentisse no desamparo, ele assumiria que seu filho também o estivesse. Essa confusão entre os estados mentais da criança e os do genitor poderia ser concebida como resultado de uma falta de diferenciação do eu-não-eu neste último. O genitor também poderia ter uma tendência em refletir o desamparo da criança sem lhe mostrar indicadores que lhe permitam descobrir a natureza representacional e não real de seu estado mental. Esse reflexo, muitas vezes realizado sem modulação, dá ao estado de espírito da criança 
um valor de realidade. Nesse contexto, a criança compreende que os estados mentais são contagiosos e até mesmo perigosos (Leroux \& Terradas, 2013).

Do lado da criança, a preponderância do modo de equivalência psíquica pode se produzir quando o pai ou a mãe são capazes de se afinar emocionalmente com o estado interno da criança, mas sem conseguir refletir seus afetos de modo marcado e conter seu desamparo (Fonagy et al., 2002). Assim, um ou outro não contribuem para a simbolização e a interpretação dos estados internos para a criança. Consequentemente, os estados internos em que a criança não pode pensar são vividos como excessivamente reais (Fonagy \& Target, 1996). Quando o desamparo é mal regulado por um dos pais, a criança pode compreender que ela provoca neles um desamparo equivalente (e depois eventualmente em outrem). A predominância do modo de equivalência psíquico poderia ser ilustrado, por exemplo, por uma criança que diz saber o que os outros pensam, que atribui aos outros suas emoções, que está convencida de que o que a habita é destrutivo para os outros ou que pena em fazer semblante, pois o jogo é para ela muito real (Domon-Archambault \& Terradas, 2012).

\section{Preponderância do modo fictício}

$\mathrm{O}$ (a) genitor(a) que funciona (quase) exclusivamente segundo o modo fictício não está em medida de refletir adequadamente os estados mentais de seu filho, pois não está em contato com sua própria experiência afetiva (Leroux \& Terradas, 2013). É possível que ele evite pensar em seus próprios estados mentais (Fonagy \&Target, 1996).

Com relação à criança, um funcionamento mental marcado pela primazia do modo fictício pode ocorrer quando um dos pais não conseguiu se afinar com o que a criança expressa (Fonagy et al., 2002). O genitor lhe refletiu emoções marcadas, mas em razão de uma falta de sensibilidade ou de congruência, essas emoções não correspondem à sua experiência. A atitude do pai ou da mãe a leva a pensar que seu mundo interno não está ligado à realidade externa (por exemplo, ao que o genitor reflete), nem ao que ela sente (por exemplo, suas próprias sensações) (Domon-Archambault \& Terradas, 2015). A criança também pode ser levada a crer que os outros não podem compreender seus estados mentais ou que eles não se interessam 
por eles. A regulação afetiva de uma criança que funciona mais no modo fictício será feita fora da relação com outrem, por meio de um jogo ou de um discurso totalmente desconectado de sua experiência interna (Fonagy \& Target, 1996). A primazia do modo fictício seria ilustrada por uma criança que recorre à dissociação, que apresenta um discurso vazio ou falsamente maduro, que racionaliza ou que não consegue identificar seus estados mentais, mas pode fazê-lo em relação aos outros (Domon-Archambault \& Terradas, 2012).

\section{Intervenções baseadas na mentalização, uma prática educativa alternativa na proteção da infância}

O programa de intervenções baseadas na noção de mentalização se dirige principalmente aos educadores que trabalham com crianças e adolescentes residindo em diversos meios especializados depois da intervenção da proteção da juventude. Entretanto, esse programa poderia ser adaptado a outros meios de intervenção (por exemplo, unidades de hospitalização psiquiátrica ou hospitais-dia para crianças e adolescentes). Inscrevendo-se na linhagem dos trabalhos de Fonagy e de seus colegas, essas intervenções têm o objetivo de promover uma atitude positiva em relação à capacidade nos educadores e aumentar a capacidade de mentalização nos jovens. Essa abordagem é baseada na relação de apego que a criança ou o adolescente pode desenvolver com uma nova figura significativa com a qual ela interage no dia a dia, ou seja, com seu educador de acompanhamento que trabalha com os jovens em suas atividades cotidianas e que faz intervenções com eles.

Considerando-se a hipótese de que o educador possa oferecer uma experiência emocional reparadora que permite à criança ou ao adolescente viver um laço de apego assegurador com ele, Domon-Archambault e Terradas (2012) desenvolveram um programa de intervenção visando exclusivamente o trabalho desses interventores cujas funções se parecem com um acompanhamento parental. $\mathrm{O}$ objetivo central dessas intervenções é o de dar suporte ao jovem no aprendizado da mentalização em situações emocionalmente carregadas, próximas da vida diária, para que ele possa expressar e regular suas emoções sem transbordamento. 
Domon-Achambault e Terradas (no prelo) sustentam que a utilização das intervenções baseadas na mentalização no contexto da proteção da juventude encerra várias vantagens. Primeiro, esse tipo de intervenção se aplica a todas as crianças e adolescentes em abrigo, pouco importando a severidade ou a natureza de seu quadro clínico. Depois, essa abordagem pode ter um impacto na propensão aos atos e sobre a agressividade das crianças e adolescentes, atenuando assim suas consequências negativas sobre os outros jovens e sobre os intervenientes. Em terceiro lugar, as crianças em abrigo evoluem em um contexto que se parece como o meio familiar, com determinantes emocionais e afetivos similares aos que as crianças e adolescentes poderiam viver em seu meio familiar. Finalmente, esse trabalho não requer ao interventor aprendizagens totalmente novas, mas sim observar e depois melhorar seu modo de intervir.

Os princípios diretores que orientam as intervenções propostas dizem respeito à diminuição dos atos em benefício da regulação afetiva pelo pensamento reflexivo no jovem, bem como uma melhor gestão das reações que provocam comportamentos no educador, permitindo a esse último intervir com mais proximidade sobre as necessidades da criança (Domon-Archambault \& Terradas, 2012). Seis parâmetros principais estruturam as intervenções:
1. Sentimento de segurança. $O$ educador deve transmitir ao jovem um sentimento de segurança para que ele esteja apto a considerar seus estados mentais e os de outrem. Como sugerido por Allen et al. (2008), as intervenções baseadas na mentalização são feitas em geral antes ou depois de uma crise. No momento da crise, a criança ou o adolescente funciona constantemente segundo um modo teleológico. Sua capacidade de pensar estando muito reduzida, o primeiro objetivo é de acalmá-lo. A presença do educador permite assegurar a criança ou o adolescente e restabelecer o nível de funcionamento de sua capacidade de mentalização.

\section{Empatia com o que não é} dito. A natureza de suas dificuldades faz com que, muitas vezes, os jovens em abrigo se expressem primeiro com gestos mais do que com palavras, o que deve ser considerado como uma expressão de si, ainda que inadequada. Convém então ajudá-los a pensar o que eles expressam por seu comportamento (Verheugt-Pleiter et al., 2008). Nesse sentido, é importante valorizar a expressão em palavras, ainda que inadequada, mais do que a ação. Não se trata de encorajar o jovem a se expressar de modo impróprio, mas de aceitar, renomear adequadamente e considerar os estados mentais subjacentes.

3. Mentalização. É importante diminuir as intervenções não-mentalizantes em benefício de intervenções mentalizantes durante o trabalho com 
jovens em situação de vulnerabilidade. Uma intervenção mentalizante se caracteriza pela reflexividade, pelo dinamismo (por exemplo, ser ativo, fazer perguntas), pela utilização do humor e de metáforas, pela espontaneidade, criatividade, curiosidade, pelo grande bom senso e pela abertura de espírito (Allen et al., 2008). As intervenções mentalizantes são centradas essencialmente sobre o aqui e agora, isto é, sobre o que se passa no contexto da relação entre o jovem, o educador e as outras crianças ou adolescentes alojados no centro. Elas têm como objeto o espírito do jovem, mais do que um comportamento preciso, sustentando assim a atribuição de um sentido ao comportamento observado.

4. Colaboração. Considerando-se que a mentalização é uma capacidade que se desenvolve no quadro de uma relação, os atores dessa relação devem estar implicados para que o processo possa se instalar. Aliás, as intervenções baseadas na mentalização têm como objetivo tornar o jovem um colaborador ativo para que ele eventualmente aprenda a mentalizar sozinho ou com outrem. Essa abordagem implica em que o educador assuma uma posição do tipo: não compreendemos o que se passa, mas podemos tentar compreender juntos. Essa posição supõe uma reflexão conjunta, em voz alta, para refazer a sequência dos acontecimentos ou para emitir hipóteses quanto ao que se passa. É importante trabalhar no limite da capacidade do indivíduo, ou seja, suficiente próximo desses limites para que ele entenda que pode conseguir sozinho, mas bastante longe para que isso represente um desafio e que ele precise de um pouco de suporte (Allen et al., 2008).

5. Jogo e abordagem positiva. Uma abordagem baseada na noção de mentalização implica jogar com as ideias, imaginar diferentes possibilidades, fazer semblante, criar metáforas, fazer brincadeiras e se colocar no lugar do outro. A abordagem baseada na mentalização propõe aos educadores brincar o máximo possível. Ela sugere que uma intervenção não deve estar necessariamente associada às dificuldades da criança, a um período de crise ou a um transtorno. Ela privilegia uma intervenção que 
favorece a mentalização na vida diária, mais do que uma intervenção que só ocorreria em um contexto de dificuldades. Nesse sentido, uma intervenção centrada sobre um estado mental "positivo" teria tanto valor terapêutico, quanto uma intervenção relativa a um estado mental "negativo" com crianças e adolescentes em situação de abrigo, com sérias dificuldades no plano da regulação dos afetos.

6. Uma intervenção que considera o funcionamento psíquico predominante no jovem. Para que se possa contribuir para o desenvolvimento da capacidade de mentalização da criança ou do adolescente, é preciso primeiro ser sensível às manifestações que demonstram o nível de mentalização da criança. Com isso, o educador poderá em seguida adaptar suas intervenções em função do funcionamento psíquico predominante no jovem. Essa abordagem propõe objetivos e intervenções específicas dependendo do nível de mentalização dominante no jovem. Para uma descrição detalhada das diversas técnicas de intervenção, o leitor pode se referir a Domon-Archambault e Terradas (2012).

\section{Eficácia das intervenções baseadas na mentalização com crianças e adolescentes em situação de vulnerabilidade}

Um primeiro estudo piloto sobre a eficácia das intervenções baseadas na mentalização no contexto de proteção da juventude foi realizado com crianças, interventores e com o chefe de serviço de uma unidade de readaptação de um abrigo do Centro da Juventude de Laval (CJL), no Quebec. Os resultados são encorajadores. A formação e a supervisão recebidas pelos educadores sobre as intervenções contribuíram para a diminuição significativa dos sintomas de depressão, de problemas sociais, de somatização e de transtornos da atenção nas crianças participantes do estudo. A agressividade e as ações diminuíram, como esperado, mas de modo não significativo. Domon-Archambault e Terradas (2015), sugerem que uma diminuição mais pronunciada dessas manifestações implicaria na utilização das intervenções durante um período prolongado e constante. Um segundo estudo abordando a eficácia dessas intervenções com adolescentes com problemas de saúde mental abrigados no CJL está em curso. 
SUFFERING IN THE PARENT-CHILD RELATIONSHIP: MENTALIZING INTERV ENTIONS IN YOUTH PROTECTION

\begin{abstract}
Children and adolescents under the responsibility of the youth protection have experienced complex traumas concerning neglect, mistreatment, and various forms of abuse. The authors suggest that, as their parents, they show significant difficulties to mentalize as well as a pre-mentalizing mode of psychic functioning. This article presents the operationalization of the different pre-mentalizing modes of thought (teleological, psychic equivalence, and pretend-mode). This study also presents the underlying principles from a mentalizing intervention program that can be used by educators who work with vulnerable children and adolescents.
\end{abstract}

Index terms: mentalizing, trauma, pre-mentalizing modes, mentalizing interventions, youth protection.

EL SUFRIMIENTO EN LA RELACIÓN PADRE-HIJO: INTERVENCIONES BASADAS EN LA MENTALIZACIÓN ADAPTADAS A LA PROTECCIÓN DE LA INFANCLA

\title{
RESUMEN
}

La mayoria de los niños y adolescentes bajo la custodia del servicio de protección de la infancia han vivido traumas complejos relacionados con el abandono, el maltrato y diversas formas de abuso. Los autores sugieren que éstos presentan, al igual que sus padres, deficiencias significativas en cuanto a la capacidad de mentalización y un funcionamiento característico de los modos pre-mentalizadores. Este articulo presenta una operacionalización de los diferentes modos de funcionamiento mental, teleológico, equivalente y ficticio; y expone igualmente los principios subyacentes a un programa de intervención basado en la mentalización y dirigido a los educadores que trabajan con estos niños y adolescentes.

Palabras clave: mentalización; trauma; modos de funcionamiento pre-mentalizadores; intervención basada en la mentalización; protección de la infancia.

\section{REFERENNCIAS}

Allen, J. G. (2001). Traumatic relationships and serious mental disorders. Chichester, UK: John Wiley \& Sons.

Allen, J. G. (2013). Mentalizing in the development and treatment of attachment trauma. London, UK: Karnac.

Allen, J. G., Fonagy, P., \& Bateman, A. W. (2008). Mentalizing in clinical practice. Washington, DC: American Psychiatric Publishing, Inc.

Courtois, C. A. (2004). Complex trauma, complex reactions: assessment and treatment. Psychotherapy: Theory, Reasearch, Practice, Training, 41(2), 412-425. doi: 10.1037/0033-3204.41.4.412

Dodge, K. A., Pettit, G. S., Bates, J. E., \& Valente, E. (1995). Social information-processing patterns partially mediate the effect of early physical abuse on later conduct problems. Journal of Abnormal Psychology, 104 (4), 632-643. doi: http://dx.doi.org/10.1037/0021-843X.104.4.632

Domon-Archambault, V., \& Terradas, M. M. (2012). Manuel de formation aux interventions axées sur la mentalisation destiné aux éducateurs des centres jeunesse, document inédit. Sherbrooke, Canada: Université de Sherbrooke.

Domon-Archambault, V., \& Terradas, M. M. (2015). Les interventions fondées sur la notion de mentalisation auprès des enfants en situation d'hébergement. Revue québécoise de psychologie, $36(2), 1-34$. 
Domon-Archambault, V., \& Terradas, M. M. (no prelo). Efficacité d'une formation fondée sur la notion de mentalisation auprès des intervenants en centre jeunesse: étude pilote. Revue québécoise de psychologie.

Ensink, K., Bégin, M., Normandin, L., \& Fonagy, P. (2016). Maternal and child reflective functioning in the context of trauma: pathways to depression and externalizing difficulties. European Journal of Child and Adolescent Psychiatry, 7. doi: http://dx.doi.org/10.3402/ejpt.v7.30611

Ensink, K., Berthelot, N., Bernazzani, O., Normandin, L., \& Fonagy, P. (2014). Another step closer to measuring the ghosts in the nursery: preliminary validation of the Trauma Reflective Functioning Scale. Frontiers in Psychology. 5. 1-12. doi: http://dx.doi.org/10.3389/ fpsyg.2014.01471

Ensink, K., Normandin, L., Target, M., Fonagy, P., Sabourin, S., \& Berthelot, N. (2015). Mentalization in children and mothers in the context of trauma: an initial study of the validity of the Child Reflective Functioning Scale. British Journal of Developmental Psychology, 33(2), 203-217. doi: 10.1111/bjdp.12074

Fernandez, E. (2008). Unravelling emotional, behavioural and educational outcomes in a longitudinal study of children in foster-care. British Journal of Social Work, 38, 1283-1301. doi: 10.1093/bjsw/bcm028

Fonagy, P., Gergely, G., Jurist, E. L., \& Target, M. (2002). Affect regulation, mentalization, and the development of the self. Nova York, NY: Other Press.

Fonagy, P., Steele M., Steele, H., Leigh, T., Kennedy, R., Mattoon, G., \& Target, M. (1995). Attachment, the reflective self, and borderline states: The predictive specificity of the Adult Attachment Interview and pathological emotional development. In S. Dans Golberg, R. Muir, \& J. Kerr (Eds.), Attachment theory: Social, developmental, and clinical perspectives. Hillsdale, NJ: Analytical Press.

Fonagy, P., \& Target, M. (1996). Playing with reality: I. Theory of mind and the normal development of psychic reality. The International Journal of Psycho-Analysis, 77(2), 217-233.

Fonagy, P., \& Target, M. (2000). Playing with reality: III. The persistence of dual psychic reality in borderline patients. International Journal of Psychoanalysis, 81(5), 853-873.

Fonagy, P., \& Target, M. (2007). Playing with reality: IV. A theory of external reality rooted in intersubjectivity. International Journal of Psychoanalysis, 88(4), 917-937. doi: 10.1516/4774-6173-241T-7225

Gergely, G. (2003). The development of teleological versus mentalizing observational learning strategies in infancy. Bulletin of the Menninger Clinic, 67, 113-131.

Herman, J. L. (1992). Complex PTSD: a syndrome in survivors of prolonged and repeated trauma. Journal of Traumatic Stress, 5(3), 377-391. doi: 10.1002/jts.2490050305

Leroux, J., \& Terradas, M. M. (2013b). Fonction réflexive parentale et Trouble réactionnel de l'attachement: perspectives théoriques. La psychiatrie de l'enfant, 56(1), 293-315. doi: 10.3917/ psye. 561.0293

Mikic, N., \& Terradas, M. M. (2014). Mentalization and attachment representations: A theoretical contribution to the understanding of Reactive Attachment Disorder. Bulletin of the Menninger Clinic, 78(1), 34-56. doi: doi: 10.1521/bumc.2014.78.1.34.

Ogden, T. H. (1983). The concept of internal object relations. In J. S. Grotstein, \& D. B. Rinsley (Eds.), Fairbairn and the origins of object relations (pp. 88-111). Nova York, NY: Free Association Books/Guilford Press.

Ostler, T., Bahar, O. S., \& Jessee, A. (2010). Mentalization in children exposed to parental methamphetamine abuse: relations to children's mental health and behavioral outcomes. Attachment \& Human Development, 12(3), 193-207. doi: 10.1080/14616731003759666 
Target, M., \& Fonagy, P. (1996). Playing with reality: II. The development of psychic reality from a theoretical perspective. The International Journal of Psycho-Analysis, 77(3), 459-479.

Terradas, M. M., \& Achim, J. (2014). La pratique clinique en contexte pédopsychiatrique: l'apport des travaux de P. Fonagy et M. Target à la clinique d'aujourd'hui. In Comunicação oral apresentada no Colloque Fondamentaux de la clinique institutionnelle: D'hier à demain? Caen, France.

Vergheugt-Pleiter, A. J. E., Zevalkink, J., \& Schmeets, M. G. J. (2008). Mentalizing in child therapy: Guidelines for clinical practitioners. London, UK: Karnac.

Winnicott D. W. (1945). Primitive emotional development. In D. W. Winnicott, Collected papers: Through pediatrics to psychoanalysis. London, UK: Tavistock.

Winnicott, D. W. (1963). The theory of Parent and infant relationships. In P. Buckley (Ed.), Essential papers on object relations (pp. 71-101). Nova York, NY: University Press.

Winnicott, D. W. (1965). The maturational processes and the facilitating environment: studies in the theory of emotional development. London, UK: Hogarth.

Winnicott, D. W. (1968). Communication between Infant and Mother. In D. W. Winnicott, On the child (pp. 70-81). Cambridge, MA: Perseus Publishing.

Winnicott, D. W. (1971). Jeu et réalité. Paris, France: Gallimard.

miguel.terradas@usherbrooke.ca julie.achim@usherbrooke.ca 150, Place CharlesLeMoyne, Bureau 200 CP 61611 - Longueuil - QC - Canada. 